\title{
Thyroid disorders are common in first-degree relatives of individuals with type 1 diabetes mellitus
}

\author{
Débora Batista Araujo', Bianca Barone², Natasha Ferreira Teixeira \\ Melleti', Joana Rodrigues Dantas', Marcus Miranda dos Santos Oliveira', \\ Lenita Zajdenverg', Rosangela Prendim Tortora ${ }^{3}$, Mario Vaisman ${ }^{4}$, \\ Adolpho Milech' José Egídio Paulo de Oliveira', Melanie Rodacki'
}

${ }^{1}$ Department of Internal Medicine, Diabetes and Nutritional Diseases Section, Federal University of Rio de Janeiro (UFRJ) Rio de Janeiro, RJ, Brazil ${ }^{2}$ State Institute of Diabetes and Endocrinology Luiz Capriglione (IEDE), Rio de Janeiro, RJ, Brazil ${ }^{3}$ Department of Internal Medicine, Immunology Section, UFRJ,

Rio de Janeiro, RJ, Brazil ${ }^{4}$ Department of Internal Medicine, Endocrinology Section, UFRJ Rio de Janeiro, RJ, Brazil

Correspondence to:

Débora Batista Araujo de Pina Cabral Av. Epitácio Pessoa, 2990, ap. 806 22471-003 - Rio de Janeiro, RJ, Braz dbatistaaraujo@gmail.com

Received on Jan/31/2014 Accepted on Dec/11/2014

DOI: 10.1590/2359-3997000000022

\begin{abstract}
Objective: Thyroid diseases are common in individuals with type 1 diabetes mellitus (T1DM) and should be investigated annually in these individuals. The aim of this study was to evaluate the frequency of thyroid diseases in first degree relatives (FDR) of patients with T1DM. Subjects and methods: Eighty individuals (40 patients with T1DM and 40 FDR) were interviewed and blood was sampled for thyroid-stimulating hormone (TSH), free thyroxine (FT4) and thyroid peroxidase (TPO) antibodies measurement. Autoantibodies against glutamic acid decarboxylase 65 (GAD65), islet antigen-2 (IA2) and autoantibodies against insulin (AAI) were measured in FDR. Results: We found a similar prevalence of thyroid dysfunction in patients with T1DM and their FDR $(22.5 \%$ vs. $27.5 \%$; $p=$ $0,79)$. There were no differences in serum TSH levels $(p=0.29)$, FT4 $(p=0,45)$, frequency of abnormal TSH ( $p=0.28)$, positiveTPO antibodies $(p=0.13)$, titers ofTPO antibodies (in positive cases) between patients with T1DM and their FDR ( $p=0.94)$. Conclusions: Thyroid abnormalities seem to be common not only in patients with T1DM but also in their FDR, which suggests that screening strategies for thyroid diseases might also be useful to these individuals. Arch Endocrinol Metab. 2015;59(2):112-5
\end{abstract}

Keywords

Autoimmunity; diabetes; thyroid dysfunction

\section{INTRODUCTION}

$\mathrm{P}$ atients with type 1 diabetes mellitus (TIDM) are at increased risk for other autoimmune disorders, such as autoimmune thyroid disease (ATD), celiac disease and Addison's disease (1-3). The most prevalent autoimmune disease in patients with TIDM is ATD. Although quite a variable frequency of thyroid antibodies (thyroglobulin antibody $-\mathrm{TgAb}$ and thyroid peroxidase antibody - TPOAb) and thyroid dysfunction (TD) has been reported in patients with TIDM among different populations (from 3 to $50 \%$ ), a high prevalence of ATD has been reported in most cases. This suggests that both diseases share etiopathogenic mechanisms (2-6). Current guidelines recommend that all patients with TIDM should undergo an annual screening for thyroid disease with at least a serum TSH measurement $(2,6-8)$.

Clustering of autoimmune disorders is commonly observed in families of patients that have autoimmu- ne diseases. Previous studies have shown that first degree relatives (FDR) of patients with TIDM have an increased prevalence of thyroid abnormalities than the general population $(2,3,9-12)$, ranging from 8 to $25 \%$ $(2,3)$. However, these studies have included mostly Caucasians, very little is known about the prevalence of ATD in other ethnic groups and thyroid disease often remains undiagnosed in this group $(12,13)$. The aim of this study was to investigate the frequency of thyroid diseases and thyroid autoimmunity in FDR of patients with TIDM from the Brazilian multiethnic population.

\section{SUBJECTS AND METHODS}

Eighty individuals were enrolled in this study, 40 patients with TID (group 1) and their respective FDR (group 2). Patients were randomly selected, in order of appearance. All patients were followed at the Dia- 
betes and Nutritional Diseases Section at Clementino Fraga Filho University Hospital (HUCFF) of Federal University of Rio de Janeiro (UFRJ), and at the State Institute of Diabetes and Endocrinology Luiz Capriglione (IEDE) in Rio de Janeiro, Brazil. The project was approved by the institutional review board and all participants signed an informed consent.

TID was defined according to the American Diabetes Association criteria. One participant per family was included, and they were siblings or children of the index patient.

All subjects were interviewed and blood was sampled for thyroid stimulating hormone (TSH), free thyroxine (FT4) and thyroid peroxidase (TPO) antibodies measurement. Autoantibodies against glutamic acid decarboxylase 65 (GAD65), islet antigen-2 (IA2A) and autoantibodies against insulin (IAA) were also measured in the FDR. Thyroid dysfunction was defined by the presence of abnormal TSH levels and/or previous known thyroid disorder.

Serum TSH and TPO antibody were measured with a Chemiluminescence method according to the manufacturer's instructions (Immulite - Diagnostic Products Corporation). For FT4, GADA, IA2A and IAA antibodies a direct radiobinding assay (Immulite-Diagnostic Products Corporation) was used. All analyses were performed at Clementino Fraga Filho University Hospital, Rio de Janeiro, Brazil. The sera were stored at $-80^{\circ} \mathrm{C}$ degrees after sampling. Cut-off values for the test were set to $0.4-4.0 \mu \mathrm{lU} / \mathrm{mL}$ for TSH, $0.8-1.8 \mathrm{ng} / \mathrm{dl}$ for FT4, $>35 \mathrm{UI} / \mathrm{mL}$ for the positive TPO antibody, and $\geq 1.0$ $\mathrm{Ui} / \mathrm{ml}$ for positive GADA, IA2A and IAA antibodies.

All statistical analyses were performed using the Statistical Package for Social Science (SPSS). Mann-Whitney U test and Chi-Square were used for comparison between groups. A p-value $<0.05$ was considered significant.

\section{RESULTS}

\section{Characteristics of the study group}

Among TIDM patients and their FDR, there was a higher prevalence of women $(57.5 \%$ vs. $70 \%$, respectively) and Whites (62.5\% vs. 60\%, respectively). T1DM subjects were older than their FDR $(30.83 \pm 10.57$ years $v s .19 .45 \pm 9.77$ years, respectively). In patients, the mean duration of diabetes was $13.1 \pm 7.5$ years. The characteristics of the study group are shown in table 1 .
Table 1. Epidemiological characteristics and prevalence of thyroid disorders in type 1 diabetes (T1D) patients and their first degree relatives (FDR)

\begin{tabular}{lccc}
\hline Characteristics & $\begin{array}{c}\text { T1D patients } \\
\mathbf{n = 4 0}(\%)\end{array}$ & $\begin{array}{c}\text { FDR } \\
\mathbf{n = 4 0}(\%)\end{array}$ & $\boldsymbol{p}$ value \\
\hline Gender & & & \\
$\quad$ Female & $23(57.5)$ & $28(70)$ & 0.11 \\
$\begin{array}{l}\text { Ethnicity } \\
\quad \text { Whites }\end{array}$ & $25(62.5)$ & $24(60)$ & \\
$\quad$ Non whites & $15(37.5)$ & $16(40)$ & 0.20 \\
Age (mean \pm SD years) & $30.83 \pm 10.57$ & $19.45 \pm 9.77$ & 0.99 \\
$\begin{array}{l}\text { TSH level ( } \mu \text { l U/ml) } \\
\text { (mean } \pm \text { SD) }\end{array}$ & $2.32 \pm 1.78$ & $3.57 \pm 4.35$ & 0.29 \\
FT4 level (ng/dl) & & & \\
(mean \pm SD) & $1.24 \pm 0.22$ & $1.25 \pm 0.17$ & 0.45 \\
TPOAb frequency (\%) & $14(35)$ & $7(17.5)$ & 0.13 \\
$\begin{array}{l}\text { TPOAb titers (U/ml) } \\
\text { (mean } \pm \text { SD) }\end{array}$ & 280.64 & 306.14 & 0.94 \\
$\begin{array}{l}\text { Abnormal TSH level } \\
\text { frequency (\%) }\end{array}$ & $7(17.9)$ & $12(29.4)$ & 0.28 \\
$\begin{array}{l}\text { Thyroid dysfunction } \\
\text { (abnormal TSH and FT4 }\end{array}$ & & & \\
levels) frequency (\%) & $9(22.5)$ & $11(27.5)$ & 0.79 \\
TSH level $\geq 2.5(\mu l \mathrm{U} / \mathrm{ml})$ & $13(33.3)$ & $15(37.5)$ & 0.81 \\
\hline
\end{tabular}

T1D: type 1 diabetes; FDR: first degree relatives; TSH: thyroid-stimulating hormone; FT4: free thyroxine; TPOAb: thyroid peroxidase antibody.

P-value $<0.05$ was considered significant.

\section{ATD in T1DM patients and their FDR}

The prevalence of thyroid dysfunction (altered TSH and/or previous known thyroid disorder) did not differ between the groups $(22.5 \% \times 27.5 \% ; \mathrm{p}=0.79)$. A total of 8 subjects had primary hypothyroidism and were treated with levothyroxine (five patients and three FDR). These FDR had previous thyroid disease. In two of them, the correspondent index case with TIDM also had hypothyroidism. The prevalence of TSH levels $\geq$ $2.5 \mu \mathrm{lU} / \mathrm{ml}$ was also similar in both groups $(33.3 \% \mathrm{vs}$. $37.5 \%$ respectively, $\mathrm{p}=0.81$ ).

There were no significant differences in serum TSH levels $(\mathrm{p}=0.29)$, FT4 $(\mathrm{p}=0,45)$, abnormal TSH $(\mathrm{p}=$ $0.28)$, positive TPO antibodies $(\mathrm{p}=0.13)$ and titers of TPO antibodies (in positive cases) between patients with TIDM and their FDR ( $\mathrm{p}=0.94)$. Abnormal TSH levels were observed in patients and their FDR, as sho$w n$ in table 1 , and were independent of TPO antibody status $(\mathrm{p}=0.67)$. FT4 levels were normal in all patients with high TSH levels.

We found no association between TSH levels and gender $(\mathrm{p}=0.31)$, ethnicity $(\mathrm{p}=1.00)$ or age $(\mathrm{p}=$ 0.08 ) in the group as a whole or with the positivity for 
pancreatic autoantibodies $($ GADA $p=1.00$, IA2A $p=$ 0.49 and IAA $\mathrm{p}=1.00)$ in the FDR.

The prevalence of GADA in FDR was $17.5 \%(\mathrm{n}=7)$. There was a positive association between positive titers of GADA, positive TPO antibodies $(\mathrm{p}=0.00)$, and abnormal TSH levels $(\mathrm{p}=0.01)$.

\section{CONCLUSIONS}

In this study, we identified a similar frequency of thyroid dysfunction and autoimmunity in patients with TIDM and their FDR. Current guidelines indicate that thyroid disorders should be screened annually in individuals with TIDM based on the high risk of the development of these abnormalities (14-16). Our data suggests that a significant proportion of FDR also develop thyroid autoimmunity and thyroid dysfunction.

Thyroid diseases may present with non-specific signs and symptoms and may remain undiagnosed for long periods of time. Untreated thyroid diseases may increase the risk of cardiovascular diseases through inter-relationships with dyslipidemia, insulin resistance and vascular endothelial dysfunction $(17,18)$. Therefore, it is probable that FDR of patients with TIDM would also benefit by the current screening strategy for thyroid diseases that are applied for patients with TIDM.

Although we did not find any case of undiagnosed overt hypothyroidism in this study, subclinical hypothyroidism was quite common. There is increasing evidence of the role of subclinical asymptomatic hypothyroidism in the risk for cardiovascular diseases (1719) and even TSH levels between 2.5 and $4.0 \mathrm{mU} /$ liter have been linked to cardiovascular risk. The National Academy of Clinical Biochemistry has suggested that the cutoff for TSH levels should be $<2.5 \mathrm{mU} /$ liter, based on the observation that $95 \%$ of the normal population has TSH levels within this range (20). In this study, we did not find any difference in the proportion of individuals with TSH levels $<2.5 \mathrm{mU} /$ liter in patients with TIDM and FDR.

Although this study had a modest sample size, other small studies have identified similar results $(2,3,9,19,21$ 24 ), including one in another sample of the Brazilian population (12). According to these authors, thyroid autoantibodies occur in $8 \%$ to $25 \%$ of FDR of TIDM patients. The prevalence of thyroid dysfunction is also high in this group $(25 \%)$, being similar to the prevalence found in patients. These data confirm the high frequency of thyroid abnormalities in FDR of patients with TIDM and reinforce the relevance of investiga- ting thyroid disorders in family members of individuals with TIDM.

This study has also other limitations, besides its size. First, an ultrasound of the thyroid gland was not performed. Moreover, only one measurement of TSH was performed for each individual, without a confirmation of the TSH levels above the reference range. In addition, this was a cross-sectional study and information about the proportion of first degree relatives of patients with TIDM that develop clinical thyroid disease over the years is still lacking.

We did not observe any characteristic that would help to identify the FDR of TIDM that are at an increased risk of thyroid abnormalities (age, gender, family member with ATD, positive GADA, IA2 or IAA). However, some authors have found a positive association between GADA and ATD $(2,3,7,10,22-25)$. Bonifacio and cols. found a positive association between the risk of developing TPOAbs and the presence of GADA, whereas IA2A and IAA were not associated with TPO$\mathrm{Ab}$ risk in relatives of TIDM patients.

Further larger longitudinal studies are necessary to clarify if a universal screening for thyroid diseases should be recommended for FDR of patients with TIDM or if there are clinical or immunogenetic characteristics that could identify the individuals that are more prone to develop thyroid dysfunction and who should therefore undergo this investigation.

Author contributions: D.B., N.M., B.B., J.D. and M.A. researched the data, analyzed and wrote the manuscript. N.M., B.B., J.D. and R.T. recruited the patients and researched the data. M.O., M.R., L.Z., M.V., A.M. and J.E.P. reviewed and edited the manuscript.

Acknowledgements: we thank the participants and their families in this study as well as the nursing and medical staff for their help. We thank Coordenação de Aperfeiçoamento de Pessoal de Nível Superior (Capes) and Conselho Nacional de Desenvolvimento Científico e Tecnológico $(\mathrm{CNPq})$ for funding.

Disclosure: no potential conflict of interest relevant to this article was reported.

\section{REFERENCES}

1. Winter WE, Schatz DA. Autoimmune markers in diabetes. Clin Chem. 2011;57(2):168-75.

2. Bonifacio E, Mayr A, Knopff A, Ziegler AG. Endocrine autoimmunity in families with type 1diabetes: frequent appearance of thyroid autoimmunity during late childhood and adolescence. Diabetologia. 2009;52(2):185-92.

3. Hanukoglu A, Mizrachi A, Dalal I, Admoni O, RakoverY, Bistritzer $Z$, et al. Extrapancreatic autoimmune manifestations in type 1 
diabetes patients and their first degree relatives. Diabetes Care. 2003;26(4):1235-40.

4. Kordonouri 01 , Klinghammer $\mathrm{A}$, Lang EB, Grüters-Kieslich $\mathrm{A}$, Grabert M, Holl RW. Thyroid autoimmunity in children and adolescents with type 1 diabetes. Diabetes Care. 2002;25:1346-50.

5. Ramos AJS, Costa ADM, Benicio AVL, Ramos ALC, Silva ARA, de Carvalho $C R$, et al. Prevalência de doença tireoideana em pacientes com diabetes tipo 1. Arq Bras Endocrinol Metab. 2003;47(2):177-82.

6. Mantovani RM, Mantovani LM, Dias VMA. Thyroid autoimmunity in children and adolescents with type 1 diabetes mellitus: prevalence and risk factors. J Pediatr Endocrinol Metab. 2007;20(6):669-75.

7. Roldan MB, Alonso M, Barrio R. Thyroid autoimmunity in children and adolescents with type 1 diabetes mellitus. Diabetes Nutr Metab. 1999;12:27-31.

8. Souza OLR, Diehl A, Carleto Jr LD, Garcia V, Carrilho AJF, Oliveira $\mathrm{ML}$, et al. Prevalência de auto-imunidade tireoidiana em um grupo de pacientes com diabetes mellitus tipo $1 \mathrm{em}$ Londrina, PR. Arq Bras Endocrinol Metab. 2005;49(2):228-33.

9. Mohn A, Di Michele S, Faricelli R, Martinotti S, Chiarelli F. Increased frequency of subclinical hypothyroidism and thyroid-associated antibodies in siblings of children and adolescents with type 1 diabetes mellitus. Eur J Endocrinol. 2005;153:717-8.

10. Villano MJ1, Huber AK, Greenberg DA, Golden BK, Concepcion E, Tomer Y. Autoimmune thyroiditis and diabetes: dissecting the joint genetic susceptibility in a large cohort of multiplex families. J Clin Endocrinol Metab. 2009;94(4):1458-66.

11. Barone B, Dantas JR, Almeida MH, Anna-Gomes BS, BenckeGongalves MD, Albernaz MS, et al. Pancreatic autoantibodies, HLA DR and PTPN22 polymorphisms in first degree relatives of patients with type 1 diabetes and multiethnic background. Exp Clin Endocrinol Diabetes. 2011;119(10):618-20.

12. Rodrigues R, Gonçalves FT, Jorge PT. Prevalência de disfunção tireoidiana e anticorpos antitireoidianos em pacientes portadores de diabetes melito tipo $1 \mathrm{e}$ em seus familiares de primeiro grau. Arq Bras Endocrinol Metab. 2008;52(6):985-93.

13. Anaya JM, Castiblanco J, Tobón GJ, García J, Abad V, Cuervo H, et al. Familial clustering of autoimmune diseases in patients with type 1 diabetes mellitus. J Autoimmun. 2006;26(3):208-14.

14. van Belle TL, Coppieters KT, von Herrath MG. Type 1 diabetes: etiology, immunology, and therapeutic strategies. Physiol Rev. 2011;91(1):79-118.
15. de Graaff LC, Martín-Martorell P, Baan J, Ballieux B, Smit JW, Radder JK. Long-term follow-up of organ-specific antibodies and related organ dysfunction in type 1 diabetes mellitus. Neth J Med. 2011;69(2):66-71.

16. Barker JM, Barriga KJ, Yu L, Miao D, Erlich HA, Norris JM, et al.; Diabetes Autoimmunity Study in the Young. Prediction of autoantibody positivity and progression to type 1 diabetes: Diabetes Autoimmunity Study in the Young (DAISY). J Clin Endocrinol Metab. 2004;89(8):3896-902.

17. Waring AC, Cappola AR. Thyroid and cardiovascular risk. Thyroid and Heart Failure. 2009;151-65.

18. Cappola AR, Fried LP, Arnold AM, Danese MD, Kuller LH, Burke $\mathrm{GL}$, et al. Thyroid status, cardiovascular risk, and mortality in older adults. JAMA. 2006;295(9):1033-41.

19. Jin P, Huang G, Lin J, Yang L, Xiang B, Zhou W, et al. High titre of antiglutamic acid decarboxylase autoantibody is a strong predictor of the development of thyroid autoimmunity in patients with type 1 diabetes and latent autoimmune diabetes in adults. Clin Endocrinol (Oxf). 2011;74(5):587-92.

20. Kratzsch J, Fiedler GM, Leichtle A, Brügel M, Buchbinder S, Otto $L$, et al. New reference intervals for thyrotropin and thyroid hormones based on National Academy of Clinical Biochemistry criteria and regular ultrasonography of the thyroid. Clin Chem. 2005;51(8):1480-6.

21. Lam-Tse WK, Batstra MR, Koeleman BP, Roep BO, Bruining MG, Aanstoot $\mathrm{HJ}$, et al. The association between autoimmune thyroiditis, autoimmune gastritis and type 1 diabetes. Pediatr Endocrinol Rev. 2003;1(1):22-37.

22. Jaeger C, Hatziagelaki E, Petzoldt R, Bretzel RG. Comparative analysis of organ-specific autoantibodies in type 1 diabetic patients, their first-degree relatives, and healthy control subjects. Diabetes Care. 2001;24(1):27-32.

23. Kordonouri O, Hartmann R, Deiss D, Wilms M, Grüters-Kieslich A. Natural course of autoimmune thyroiditis in type 1 diabetes: association with gender, age, diabetes duration, and puberty. Arch Dis Child. 2005;90(4):411-4.

24. Bilimoria KY, Pescovitz $\mathrm{OH}$, DiMeglio LA. Autoimmune thyroid dysfunction in children with type 1 diabetes mellitus: screening guidelines based on a retrospective analysis. J Pediatr Endocrinol Metab. 2003;16(8):1111-7.

25. Bottini N, Vang T, Cucca F, Mustelin T. Role of PTPN22 in type 1 diabetes and other autoimmune diseases. Semin Immunol. 2006;18(4):207-13. 